\title{
Production of Biogas from Rice Straw Using Paddy Rice Soil as Inoculant
}

\author{
S. F. Salleh, M. R. Jalani, N. Abdul Rahman, and A. Baharum
}

\begin{abstract}
This research project is intended to study on the production of biogas from the anaerobic digestion of rice straw using paddy rice soil as the microbial inoculant. The study will be focusing on the identification of available potential feedstock from the research project's location which is Kampung Assum, investigating the suitable parameters for this digestion process and study its effects to biogas production. The parameters for the anaerobic digestion such as the ratio of soil to water and the $\mathrm{pH}$ are studied in depth in this research project while the temperature is set to be in a range of $35^{\circ} \mathrm{C}$ to $38^{\circ} \mathrm{C}$ for a mesophilic condition to be achieved. The soil to water ratio of 1:1, 1:1.5, 1:2, 1.5:1, and $2: 1$ have been done in parallel manner in fabricated biodigesters and incubator where 1:2 soil to water has produce the highest yield among all other ratios used. While for the $\mathrm{pH}$ study, a control experiment has been conducted intended for the study of the effect of $\mathbf{p H}$ on the digestion. Resulting from this study, the desirable initial $\mathrm{pH}$ for anaerobic digestion must be exceeding the $\mathrm{pH}$ value of 5.5. The combustibility test has shown a positive result where the gas produced is combusted with a blue flame without any foul smell.
\end{abstract}

Index Terms-Anaerobic digestion, rice straw, microbial inoculant.

\section{INTRODUCTION}

Power generation in rural areas has been an outstanding matter in unravelling of the energy conundrum in the whole world. The dependence on fossil fuel for power generation especially in terms of electrical power supply is perturbing as the sustainability of the fossil fuel for generations over is still a colossal issue worrying the mankind. Coals, natural gas, petroleum-derived fuels, diesel and etc. are the major types of fossil fuel combusted in order to obtain the energy which utilizes for power generation purposes in Malaysia and including other countries. In 2008, according to [1], the types of fuels used for electricity generation in Malaysia is $62.8 \%$ from natural gas, followed by $27.3 \%$ for coal and only $0.1 \%$ for crude oil. To date, there have been many studies and researches done on the matter of reducing the dependency towards fossil fuel for power generation. Renewable energy as fuel is one of the most attentive source of alternatives on energy generation where sustainability is its forte. Various forms of biomass, wind, hydro and solar are the examples of common types of renewable energies which can be implemented. However, the implementation of these alternatives are less suitable for the application in rural

Manuscript received January 27, 2016; revised May 23, 2016.

The authors are with Universiti Malaysia Sarawak, Malaysia (e-mail: sshanti@unimas.my). areas.

Masses of research projects regarding renewable energy from local available resources have been carried out so far especially its implementation in secluded or inaccessible areas. Biogas as an alternative source of energy is one of the most efficacious renewable projects that can be carried out in inaccessible villages such as Kampung Assum located in Sarawak, Malaysia. According to [2], biogas is a combustible gas which is generally composed of $60 \%$ of methane $(\mathrm{CH} 4)$ and $40 \%$ of carbon dioxide $(\mathrm{CO} 2)$, while containing trace amounts of other gases including hydrogen sulphide (H2S) with the ability to burn. With the properties comparable to natural gas, this biogas can be utilized for cooking purposes, illumination, burned in boilers or electricity generation in a small scale which is very suitable to be applied in this village.

Fermented in a biodigester under certain range of temperature, humidity and acidity, the organic waste undergone 4 backbone stages of anaerobic fermentation which are hydrolysis, acidogenesis, acetogenesis and followed by methanogenesis respectively. These processes occurrences are due to the virtue presence of microbes and bacteria which are responsible for each respective process. A study conducted by [3] on thermophilic and mesophilic digestion, it is proved that higher production of biogas can be obtained at thermophilic condition than mesophilic. On the other hand, a study conducted by [4] on various methods of pretreatment of rice straw shows that physical pretreatment utilized in the study such as cutting the rice straw into smaller size, hydrothermal and freeze has shown a positive result on the biogas yield. Addition of methanogens-rich material to the anaerobic digestion will act as a source of microbial inoculum that usually will speed up the process [5].

Paddy organic waste focusing on rice straw fermentation is the main focus of this study to produce useful biogas to be utilized in daily usage such as cooking and electricity generation. As the residents of Kampung Assum are relying on diesel generator for electricity generation, this project will significantly reduce their dependency on diesel as the fuel by proposing the utilization of biogas as a sustainable alternative source of energy to them.

\section{MEthodolOGY}

\section{A. Materials}

Rice straws and paddy rice soil were obtained from the research project location which is Kampung Assum. 
Distilled water with a neutral $\mathrm{pH}$ was used throughout the experiments. 5 basic air-tight containers and a $3 \mathrm{~mm}$ diameter tube for gas movement were bought for fabrication of the biodigesters. A portable $\mathrm{pH}$ meter was used for $\mathrm{pH}$ measuring and monitoring purposes

\section{B. Experimental Works}

There were 3 sets of experiments conducted for this research project which are control, feed ratio and $\mathrm{pH}$ test experiment. The control experiment was conducted in Solteq anaerobic digester model TR 26 for 60 days at temperature set as $35^{\circ} \mathrm{C}$ (mesophilic) with a soil to water ratio of 1:1. The feed ratio's experiment was conducted in 5 different fabricated biodigesters with soil to water ratios vary as $1: 1,1: 1.5,1: 2$. 1.5:1, and 2:1 and constant amount of rice straw, placed in an incubator in order to obtain a mesophilic condition. The initial $\mathrm{pH}$ of every biodigesters were adjusted to a $\mathrm{pH}$ greater than 5.5 with the addition of crushed chicken eggshells. The feed ratio's experiment was also ran for 60 days. Lastly, the $\mathrm{pH}$ test experiment was conducted in 5 closed beakers with the same ratio of soil to water as in feed ratio's experiment intended to monitor the $\mathrm{pH}$ changes according to digestion period and amount of water used.

\section{Combustibility Test}

The combustibility test was carried out to determine the characteristic of the gas produced from the experiment by placing a lit wooden splinter in a beaker filled with prior collected gas. The changes in the flame intensity, the flame's colour and the presence of foul smell were the characteristics to be identified in this test.

\section{RESUlTS AND DISCUSSION}

\section{A. Control Experiment}

The results are obtained from the collected data of the control experiment conducted in a study period of 60 days in the laboratory. The data are obtained from the monitoring of volume of water displaced due to the pressure exerted by the biogas produced. At mesophilic condition and controlled temperature, the digestion of rice straw will produce an amount of biogas from the microbial activity of the digestion [6]. The collected data are then analysed and transformed in to a chart. 60 days of experiment period have shown a steady result as shown in Fig. 1 below.

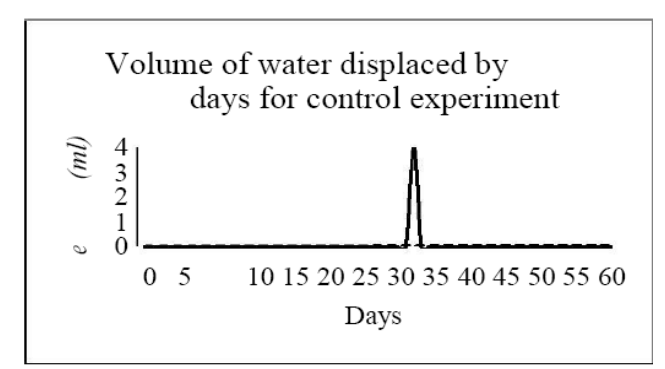

Fig. 1. The volume of water displaced by days in control experiment.

However, the results show a nil production of biogas from the anaerobic digestion of rice straw with paddy rice soil as microbial inoculant throughout the study period as shown in the Fig. 1. This result has shown a clear contradiction to the other results as proven by [6] and [7] in their research. From the first week of the experiment, evaporation of the water as shown in Fig. 2 is deducted to affect the zero yield of water displaced as the ambient temperature is quite hot and it is observed that the location of the equipment is receiving direct sunlight after noon time. Hence, it is assumed that the displaced water in the beaker is evaporated significantly by these two factors. Therefore, few steps such as covering the water collector with aluminum foil as in Fig. 3 has been done to reduce the loss due to evaporation. Yet, the production of biogas is still null. The reading recorded on the 35 th day is assumed to be due to random error which is a sudden movement of the water tank.

The failure of the liberation of biogas from this experiment is due to the inhibition of methanogenesis process. This is due to the methanogenic bacteria existed in the feedstock loaded in the digester has been killed by the acidic condition which is as asserted by both [6] and [8]. The next factor assumed is the loads of the digestion stays acidic consequently killing all the methanogenic bacteria is due to the accumulation acids in the process. Acids in the form of volatile fatty acids (VFAs) is formed as the methanogenic activity is lower than the acidogenic activity in the process. It is continuously built up in the process contributing in greater inhibition of methanogenesis process, resulting in low or null production of biogas in this experiment [6], [8]. This is explained by the slight increment of $\mathrm{pH}$ of the load measured at the end of this experiment which is averagely 4.54 .

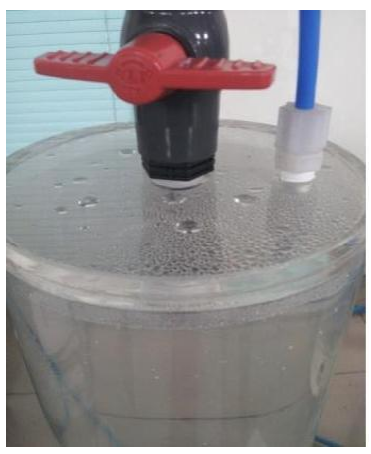

Fig. 2. Evaporation in the water tank.

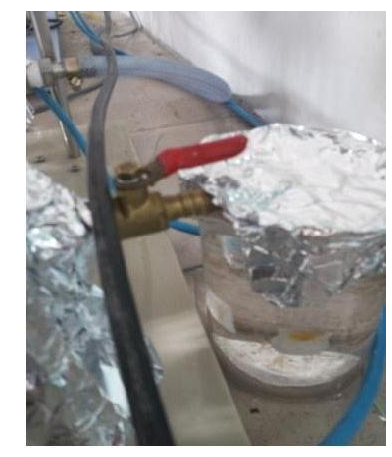

Fig. 3. Covering the water collector.

\section{B. Feed Ratio's Experiment}

The feed ratio's experiment comprised 5 sets of different experiment conducted in the fabricated biodigesters and incubator for the same period of study which is 60 days. The 5 sets of experiment are varying in term of the ratio of soil to water while maintaining the amount of rice straw loaded to each biodigester labelled as A, B, C, D and E respectively.

The difference of this feed ratio's experiment to the control experiment is the addition of crushed chicken eggshells to the feedstock loaded into the biodidgester intended to treat the acidity of the soil used as inoculant: increasing the $\mathrm{pH}$ value for a more suitable digestion as avowed by [9]. The production of biogas which is proportional to the volume of water displaced has been 
recorded as in Fig. 4 below.

From Fig. 4, the soil to water ratio of 1:2 has the highest amount of biogas collected as observed. The volume of water is greater than the amount of water filled. Among 5 different ratios used, 1:2 gives the best result. The higher amount of water used is suitable in creating anaerobic condition as it slows down the movement of oxygen in the feedstock which is approaching to stagnant. Anaerobic condition requires a low oxygen content in order to be created. Thus, with a higher amount of water used to be mixed with the feedstock, the better the anaerobic condition.

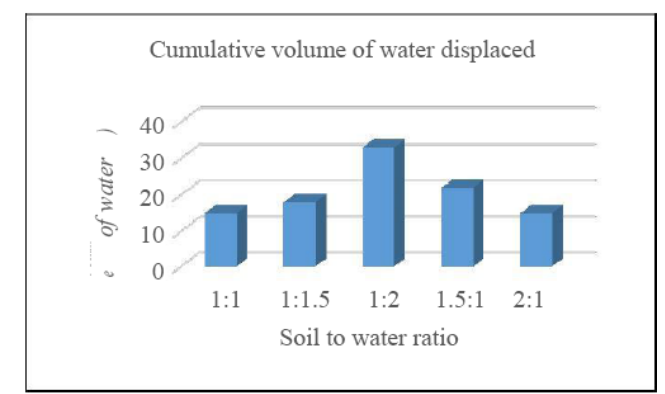

Fig. 4. Cumulative volume of water displaced in feed ratio's experiment.

\section{Effects of pH on the Anaerobic Digestion of Rice Straw}

The ideal $\mathrm{pH}$ range for anaerobic digestion of rice straw was suggested to be between 7.5 to 8.0 [10]. A comparison study between the control experiment and feed ratio's experiment $(1: 1)$. Both of these sets of experiment are conducted with similar ratio of soil to water in the loads where the amount of rice straw is kept constant. The difference between these two sets of experiment is the addition of crushed eggshells which is intended to increase the $\mathrm{pH}$ value of the loads which have resulting in positively. A related study [11] focused on the crushed eggshell performance acted as a neutralizing agent of the soil in comparison with other common agent used in the agriculture such as agricultural lime

Each of biodigesters in feed ratio's experiment were added with crushed chicken eggshell to adjust the $\mathrm{pH}$ to be above 5.5 while in the control, the experiment is run on lower $\mathrm{pH}$ without any adjustment. The result of changing $\mathrm{pH}$ is as shown in Fig. 5 below where there is production of biogas in feed ratio's experiment set compared to control set.

The $\mathrm{pH}$ adjustment for all 5 sets of biodigesters to be above a reading of 5.5 by adding crushed chicken eggshells has shown a positive result where there is production of biogas in all 5 sets of biodigesters compared to the control experiment where the $\mathrm{pH}$ is left to be acidic. The production of biogas for all sets are summarized in Fig. 6.

\section{D. pH Test Experiment}

The $\mathrm{pH}$ test experiment is intended to monitor the changes in $\mathrm{pH}$ throughout the period of study which is 60 days prior to the presumptions that the $\mathrm{pH}$ will be increasing with the volume of water added and the days of fermentation. It was conducted in 5 sets of closed beaker with varying soil to water ratios. At the commissioning of the experiment, the initial $\mathrm{pH}$ of all 5 sets of ratio are ranging from 3.30 to 3.55 . As observed and recorded, the changes of the $\mathrm{pH}$ in each sets were plotted in a graph as shown in Fig. 7 below. Revealed by the results, the $\mathrm{pH}$ changing trend of all different ratios used are observed to be increasing throughout the end of the experiment. The distribution of $\mathrm{pH}$ recorded was steady at every recorded time as the points shown in the graph are not heavily scattered. Despite the fact that the $\mathrm{pH}$ is increasing according to time, approaching the ending of the experiment however it shows that, the $\mathrm{pH}$ value for all ratios done have never been exceeding $\mathrm{pH}$ value of 5 . This condition is still too acidic for methanogenic bacteria to live on. Thus, this strengthen the assumption done on the null production of biogas in the control experiment previously.

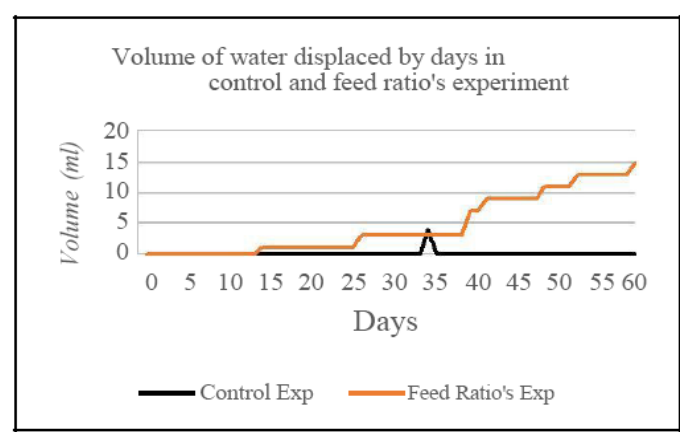

Fig. 5. Comparison on the production of biogas in control and feed ratio's experiment.

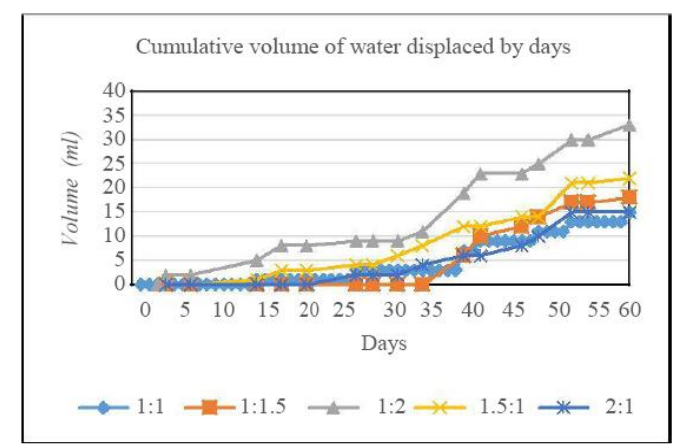

Fig. 6. Cumulative volume of water displaced for all biodigesters.

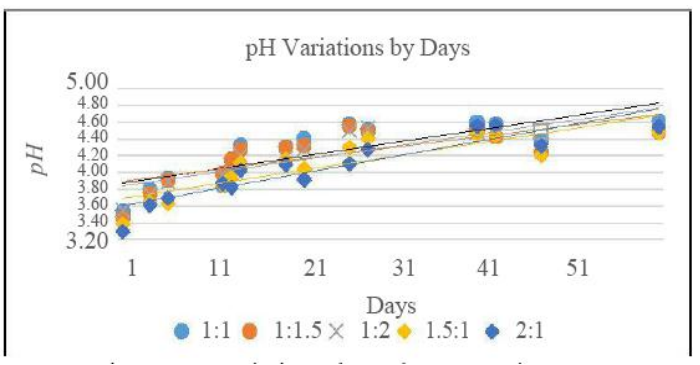

Fig. 7. $\mathrm{pH}$ Variations throughout experiment.

\section{CONCLUSION}

This research project is intended to study production of biogas from the anaerobic digestion of rice straw using paddy rice soil as the microbial inoculant which is going to be utilized in Kampung Assum, Sarawak. Located in the higher ground area of Padawan and considered as one of the rural areas in Sarawak, the residents are still relying on diesel generator for electricity generation. Intended to 
reduce the dependency of the resident on fossil fuel, this biogas project is able to be utilized for both power generation and cooking requirement.

\section{A. Control Experiment}

Number The experiment is done based on the soil to water ratio of $1: 1$ in a 60 days period of study. The temperature is set to be $35^{\circ} \mathrm{C}$ which is according to the mesophilic condition. The initial average $\mathrm{pH}$ value of the substrate is recorded as 3.98 which was quite acidic. The low $\mathrm{pH}$ value was presumed to increase along the period of study and in the same time, aiding in the breaking down of lignocellulosic structure of the rice straw. However, the presumptions are not happening and due to high acidity of the topsoil obtained from Kampung Assum, there is null production of biogas from this digestion since it is completely inhibited by the acid accumulation in the feedstock. There are also several random errors such as evaporation losses and sudden drastic movement of the equipment might have occurred. Nevertheless, the precaution steps such as doing signage and covering the water collector with aluminium foil has been done.

\section{B. Feed Ratio's Experiment}

The feed ratio's experiment comprises 5 sets of different experiment conducted parallel for 60 days in 5 fabricated biodigesters. In addition, in order to achieve a mesophilic condition, an incubator also fabricated using plywood and the heat source is the embedded menthol in the incubator itself. The 5 sets of experiments are varying in terms of the soil to water ratio which are $1: 1,1: 1.5,1: 2,1.5: 1$ and $2: 1$. The initial $\mathrm{pH}$ of these biodigesters are measured as quite low, therefore crushed eggshells is added to the substrates until the $\mathrm{pH}$ were above 5.5. Among the 5 sets, the ratio of 2:1 had displaced the highest amount of water displaced. Hence, this ratio is deduced to be the best in the ranges of ratios used. On top of that, all these 5 sets experiments resulted in a steady increase of cumulative volume of water displaced throughout the period of study. Therefore, altering the $\mathrm{pH}$ value to a suitable value is vital in order to prevent the inhibition of methanogenesis in the process.

\section{C. $p H$ Test Experiment}

The $\mathrm{pH}$ test experiment's purposes are to monitor the $\mathrm{pH}$ changing in the control and feed ratio's experiment, to study on the presumptions done on the effect of volume of water towards the $\mathrm{pH}$ and the increment of $\mathrm{pH}$ value along the time of period of study. Though the $\mathrm{pH}$ value of the mixture is increasing sturdily towards time, the maximum $\mathrm{pH}$ value of all mixtures are not even close to 5. This contradicts the presumptions done. In addition, from the result of this test, it can be deduced that null production of biogas in the control experiment is due to high acidity of the substrate.

\section{ACKNOWLEDGMENT}

The authors would like to thank Centre of Renewable Energy (CREN) Unimas for funding this research and Universiti Malaysia Sarawak for the research facilities provided

\section{REFERENCES}

[1] A. M. Yusof, Z. M. Nopiah, and K. Sopian, Modelling Electricity Generation in Malaysia Using IMEM: Initial Results, PROSIDINGPERKEM VII, JILID 1, 2012, pp. 1-5.

[2] L. E. Erickson and Y. C. Fung, Handbook on Anaerobic Fermentations, Marcel Dekker Inc., New York, 1988.

[3] S. Harikishan and S. Sung, "Cattle waste treatment and class A biosolid production using temperature-phased anaerobic digester," Adv. in Environmental Research, vol. 7, 2003.

[4] F. P. Sari and Budiyono, "Enhanced biogas production from rice straw with various pretreatment: A review," Master thesis, Dipnegoro University, Jawa Tengah, Indonesia, 2014.

[5] F. Xu, "Experimental studies and modelling of solid state anaerobic digestion for enhanced methane production from lignocellulosic biomass," Doctoral thesis of environmental science, the Ohio State University, 2014.

[6] W. Mussoline, "Enhancing the methane production from untreated rice straw using an anaerobic co-digestion approach with piggery wastewater and pulp and paper mill sludge to optimize energy conversion in farm-scale biogas plants," Earth Sciences, Universit'e Paris-Est; Universit'e de Cassino, 2014.

[7] P. Gupta et al., Study on Biogas Production by Anaerobic Digestion of Garden-Waste, Elsevier Ltd., 2011.

[8] W. W. Haan, "Evaluation of ultrasonic pretreatment on anaerobic digestion of biomass for methane production," Iowa State University, 2008.

[9] C. N. Acharya, "Studies on the anaerobic decomposition of plant materials; some factors influencing the anaerobic decomposition of rice straw (Oryza Sativa)," Fermentation Department, Rothamsted Experimental Station. Harpenden, 1935.

[10] W. Mussoline, Esposito, A. Giordano, and P. Lens, "The anaerobic digestion of rice straw: A review," Critical Review in Environmental Science and Technology, vol. 43, no. 9, pp. 859-915, 2013.

[11] C. Mitchell, "Crushed eggshells in the soil," Agricultural and Natural Resources, University of Agronomy \& Soils, Auburn University, 2005.

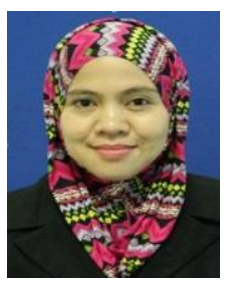

Shanti Faridah Salleh was born on September 7, 1977 in Malaysia. Her first degree BEng was obtained from Loughborough University, England. Her master degree in advanced proces engineering also from Loughborough University. Her PhD degree is from Universiti Putra Malaysia. Her research areas include biomass and bioenergy, process engineering and environmental management. She is a senior lecturer who currently holds the position of the head of Department in Chemical Engineering and Energy Sustainability, Faculty of Engineering, Universiti Malaysia Sarawak.

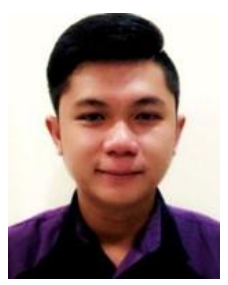

Mohd Rahmat Jalani is an undergraduate student with the Department of Chemical Engineering and Energy Sustainability, Faculty of Engineering, Universiti Malaysia Sarawak (UNIMAS)

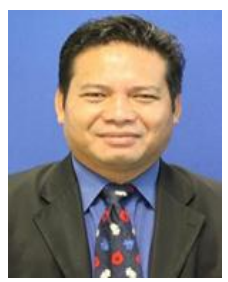

Nazeri Abdul Rahman is a senior lecturer with the Department of Chemical Engineering and Energy Sustainability, Faculty of Engineering, Universiti Malaysia Sarawak (UNIMAS).

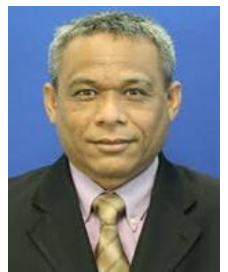

Azhaili Baharun is a director of the Centre of Renewable Energy (CREN), Faculty Of Engineering, Universiti Malaysia Sarawak. 